\title{
MUSEU DO AMANHÃ E ARTICULAÇÕES DA EXPRESSÃO TECTÔNICA E CONDIÇÃO CENOGRÁFICA
}

\section{MUSEUM OF TOMORROW AND ARTICULATIONS OF TECTONIC EXPRESSION AND CENOGRAPHIC CONDITION}

\author{
Diogo Ubaldo Braga ${ }^{1}$ \\ Universidade Federal de Minas Gerais, Belo Horizonte, MG, Brasil, diogoubaldobraga@gmail.com
}

Maria Luiza Almeida Cunha de Castro²

Universidade Federal de Minas Gerais, Belo Horizonte, MG, Brasil, luizadecastro@ufmg.br

Marco Antônio Penido de Rezende ${ }^{3}$

Universidade Federal de Minas Gerais, Belo Horizonte, MG, Brasil, marco.penido.rezende@hotmail.com

João Luiz van Ham Mello ${ }^{4}$

Universidade Federal de Minas Gerais, Belo Horizonte, MG, Brasil, joaoluizvanham@gmail.com

\begin{abstract}
Resumo
Este artigo parte de uma análise da arquitetura dos novos museus globais, escolhidos como objeto de pesquisa devido a seu conteúdo simbólico subjacente. Adotando uma abordagem qualitativa, a investigação procura confrontar o conceito de "tectônica" a questionamentos relativos à utilização de elementos cenográficos na arquitetura museal contemporânea, incorporando ainda considerações sobre o uso destas edificações. A ideia de tectônica parte da relação que a dimensão material, construtiva e tátil da arquitetura estabelece com sua expressão plástica, uma questão que foi colocada em pauta em meados do século XIX e recentemente reemergiu por meio de reflexões tais como as de Kenneth Frampton e Gevork Hartoonian. Sob a luz de conceitos propostos por estes autores, da crítica à arquitetura tardo moderna, a partir de Venturi, Brown e Izenour e de considerações sobre a condição cenográfica da arquitetura - propõe-se uma investigação sobre o Museu do Amanhã, Rio de Janeiro. O objetivo é questionar se a mera expressão tectônica do edifício é capaz de isentá-lo de qualquer intenção de espetáculo e cenografia. Embora nitidamente inserido dentro de uma dinâmica de competição de cidades, a partir da criação de uma imagem de marca, o Museu destaca uma solução construtiva e estrutural em que as relações de carga e apoio se expressam em coerência com a forma. Reafirma-se desta forma as possibilidades de articulação entre expressão tectônica e cenografia, materialidade e imagem.
\end{abstract}

Palavras-chave: Tectônica. Cenografia. Arquitetura. Museu. Globalização.

\begin{abstract}
This article departs from an analysis of the new global museum architecture, chosen as the research focus due to their underlying symbolic content. The research seeks to confront, adopting a qualitative approach, the concept of "tectonics" to the use of scenography elements in Contemporary museum architecture. It also incorporates considerations on the use of these Buildings. The idea of tectonics originates from the relationship that the material, constructive, and the tactile dimension of architecture establishes with its plastic expression. This discussion was brought up in the mid-nineteenth, and it has recently reemerged through reflections such as those of Kenneth Frampton and Gevork Hartoonian. Under the light of concepts proposed by these authors, Venturi, Izenour, Brown's criticism of tardo-modern architecture, and considerations about the scenography condition of architecture, the research proposes an investigation about the Museu do Amanhã (Museum of Tomorrow), in Rio de Janeiro, Brazil. The purpose is to question whether the mere tectonic expression of the building is capable of exempting it from any intention of spectacle and scenography. Although it is part of a strategy that attempts to create a brand image for the city, the Museum highlights a constructive and structural solution in which the relations of load and support are expressed in coherence with the form. Therefore, it states the possibilities of articulation between tectonic expression and scenography, materiality, and image.
\end{abstract}

Keywords: Tectonics. Scenography. Architecture. Museum. Globalization.

How to cite this article:

BRAGA, D. U.; CASTRO, M. L. A. C. DE; REZENDE, M. A. P. DE; MELLO, J. L. VAN H. Museu do Amanhã e articulações da expressão tectônica e condição cenográfica. PARC Pesquisa em Arquitetura e Construção, v. 11, p. e020012, 14 jul. 2020. DOI: https://doi.org/10.20396/parc.v11i0.8655866 


\section{Introdução}

A tradição dos museus públicos do século XIX adotou a tipologia dos templos antigos para abrigar suas obras e alimentou todo um imaginário coletivo que associa os museus a edifícios antigos.

Em meados do século XX, esta tipologia dominante começou a ser abandonada, substituída, inicialmente pelas ideias modernistas/racionalistas na arquitetura que desde o início do século se alinhavam com as vanguardas artísticas em seu questionamento quanto aos edifícios que abrigavam os velhos museus nacionais e suas coleções. Os primeiros museus da nova geração buscaram cristalizar no tempo uma expressão da técnica vigente à época, posicionamento coerente com o racionalismo: a expressão formal do edifício museológico descolou-se da correspondência com o monumento histórico para se compatibilizar com a razão construtiva.

A primeira onda de renovação ocorreu com a construção de museus tais como o Guggenhein de Frank Lloyd Wright em Nova York (USA, 1959), a Fundação Maeght de Josep Lluís Sert, em Saint-Paul-de-Vence (França, 1964) ou a Kunsthalle de Philip Johnson, em Bielefeld (Alemanha,1968). No Brasil, edifícios representativos desta tendência foram o Museu de Arte Moderna do Rio de Janeiro de Reidy (1954) e o Museu de Arte Moderna de São Paulo de Lina Bo Bardi, (1957) (MONTANER, 1995; KIEFER, 2001).

A relação do envelopamento com a contemporaneidade se tornou tão mais coerente, quanto mais a ideia de patrimônio se tornou abrangente, posto que os edifícios museais deixavam de ser unicamente receptáculos de monumentos históricos, e passavam a abrigar também outras formas de manifestação cultural, mesmo que recente, como, por exemplo, a arte contemporânea (CHOAY, 2006).

Porém, o denominador comum entre as diferentes propostas para as novas edificações passou a ser o foco na imagem, que se sobressai com relação ao entorno, com tendência ao espetacular e apelo publicitário (CHOAY, 2006). Este tipo de arquitetura se coloca como parte do aparato de marketing das cidades globais (SASSEN, 2001), gerando questionamentos quanto ao objetivo de sua expressão plástica que cria uma cenografia destacada.

O artigo apresenta o conceito de tectônica e se desenvolve a partir do questionamento das articulações entre uma arquitetura com expressão formal, que reflete seus aspectos construtivos (tectônica), e uma arquitetura que oculta ou obscurece a relação entre materialidade e forma (atectônica). A metodologia de pesquisa incluiu uma revisão bibliográfica com foco na perspectiva de Frampton (1983, 1990, 1995) e Hartoonian (2016) sobre o tema, autores fundamentais para uma discussão que contempla ao mesmo tempo a análise das tendências globalizantes e sua inserção dentro de um contexto local. Colocando em pauta os antagonismos entre pós-modernismo e hightech (RAMÍREZ-MONTAGUT,1998) e imagem e materialidade - Frampton e Hartoonian analisam as tensões e confrontos decorrentes. Procura-se, então, neste artigo, demonstrar que nem toda arquitetura tectônica é isenta de um valor cenográfico, uma vez que a própria abordagem tectônica permite vislumbrar a conciliação das contradições. Como contraponto para esta perspectiva, adota-se os arquétipos de "pato" e "galpão decorado" utilizados na crítica de Venturi, Brown e Izenour (2003) à arquitetura tardo-moderna. A visão de Venturi, um dos precursores da crítica contemporânea à arquitetura moderna, foi fundamental para as manifestações e tendências arquitetônicas posteriores e entende-se que as suas colocações continuam pertinentes quando aplicadas à arquitetura dos novos museus contemporâneos, mesmo àqueles de expressão formal tectônica. 
A reflexão teórica se concretiza a partir da análise do Museu do Amanhã, projeto do arquiteto espanhol Santiago Calatrava, construído no Rio de Janeiro no período que antecedeu os grandes eventos internacionais de que o Brasil foi palco: a Copa do Mundo de futebol (2014) e os Jogos Olímpicos (2016). A partir da identificação das estratégias que situam a arquitetura como instrumento de marketing na competição global entre as cidades - cuja expressão máxima continua sendo o Museu Guggenheim de Bilbao na Espanha - as tensões existentes no Museu do Amanhã são investigadas. As relações entre uso, função, imagem, significado, materialidade e espaço se refletem, desta forma, no confronto entre tectônica e cenografia.

Embora nitidamente inserido dentro de uma dinâmica de competição de cidades, buscando a criação de uma imagem de marca, o Museu do Amanhã adota uma solução construtiva e estrutural em que as relações de carga e apoio se expressam em coerência com a forma. Reafirma-se desta maneira, as possibilidades de articulação entre expressão tectônica e cenografia, materialidade e imagem, cultura e civilização.

\section{Frampton e a dicotomia tectônico-atectônico}

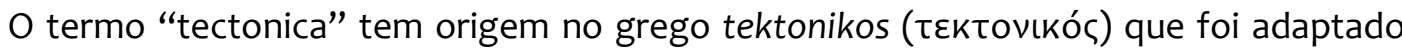
para o latim como "tectonicus", significando construtor ou carpinteiro (CANTALICE II, 2018, p. 248; FRAMPTON, 1995, p.g3). No campo da arquitetura, a ideia se entrelaçou com diversos aspectos da construção e cultura: neste âmbito, sua primeira utilização em alemão teria sido em 1830, por parte de Otfried Muller, e dizia respeito a uma série de objetos e até edificações, pensados a partir sua utilidade, mas, também, de "[...] sua conformidade com sentimentos e noções de arte" (FRAMPTON, 1995 p. 4). Na mesma época (entre 1843 e 1852), Botticher trouxe uma interpretação do templo grego que aplicava o termo tectônica para explicar o sistema de relações entre todas as suas partes, capaz de formar "um todo único" (FRAMPTON, 1995, p. 5).

Porém, um dos autores que mais contribuiu para a discussão do conceito no século XIX foi Semper, que se baseou da interpretação da construção de uma cabana caribenha na exposição Universal de Londres, em 1851. A partir de quatro técnicas tradicionais - o têxtil, a cerâmica, a tectônica (carpintaria), e a estereotomia (corte das pedras) Semper classificou os procedimentos empregados em tectônicos e estereotômicos ${ }^{3}$ (FRAMPTON, 1995; HARTOONIAN, 2016).

Esta foi uma época de intensas mudanças nas relações da produção construtiva e, em suas diferentes nuances, os três autores enxergavam a tectônica enquanto "[...] uma teoria capaz de guiar a maneira como uma edificação seria erigida por meio do entendimento de seu processo de construção e da herança de construção de um lugar" (CANTALICE II, 2018, p. 249). Semper, em especial, procurou uma relação estreita com a nascente ciência da etnografia, que estava sendo estruturada naquela época (FRAMPTON, 1995)

A discussão sobre a tectônica foi colocada de lado na primeira metade do século XX, sendo retomado na década de 1960, por Eduard Sekler e Peter Collins, passando, a partir de então, a ser debatido por críticos e historiadores tais como Kenneth Frampton, Edward Ford, Ulrich Pfammatter, Gevork Hartoonian, Andrea Deplazes, Regean Legault, David Leatherbarrow, entre outros (CANTALICE II, 2018). Foi, portanto, Sekler (1965) que resgatou o termo tectônica (FRAMPTON, 1995), com o objetivo de tecer críticas à arquitetura tardo-moderna e a sua produção, composta por edificações com um excesso de articulação formal.

Na mesma época, desenvolvia-se, também, a crítica pós-moderna, subsidiada pelo argumento de que as edificações modernistas careciam de significado. Esta crítica foi 
iniciada com "Complexidade e Contradição em Arquitetura" (1966) e foi posteriormente alimentada por "Aprendendo com Las Vegas" (1972), que inseriu dois arquétipos irônicos, usados pelos autores Venturi, Brown e Izenour (2003), para classificar a arquitetura moderna tardia produzida à época: "patos" e "galpões decorados" (p. 118). O "galpão decorado" era, para os autores, uma caixa simples com signos aplicados como um outdoor com aplicação de ornamentação em sua fachada. Por sua vez, o termo "pato" - inspirado por um grande edifício em formato de pato - dizia respeito a edifícios cuja estrutura e volume se apresentavam como o próprio ornamento que, mesmo com intenções metafóricas, tendiam ao figurativo (VENTURI; BROWN; IZENOUR, 2003, p.183)'. Estes foram o fundamento e as bases de todo um movimento pós-moderno, que defendia uma arquitetura simbólica, comunicativa, historicista, menos abstrata, resultando em diversas apropriações de símbolos históricos e em um retorno a uma certa forma de ornamentação (JENCKS, 2011).

Sekler e a crítica tectônica, por outro lado, pregavam um retorno a uma relação inseparável entre forma e força estática da construção, entre a expressão artística da edificação e sua lógica construtiva. Embora focadas na arquitetura tardo moderna, as questões colocadas em pauta por esta crítica atingiam também a arquitetura pósmoderna, posto que esta, desenvolvendo-se em busca de edificações simbólicas, produzia arquiteturas cenográficas, como o próprio Venturi relata após uma revisita a Las Vegas.

As características imagéticas, formais e simbólicas da produção arquitetônica pósmoderna reacenderam, portanto, o debate crítico sobre o tema, que foi retomado por Kenneth Frampton na década de 1980, a partir da perspectiva da tectônica na arquitetura, apresentada e discutida em três obras: Towards a critical regionalism: Six points for an architecture of resistance (1983), Rappel à l'orde: The case for the tectonic (1990) e Studies in tectonic culture (1995). Nas duas primeiras obras, Frampton "insiste na dimensão material, construtiva e tátil da arquitetura, representada pelo conceito de tectônica, como uma forma de oposição à abordagem cenográfica do modernismo tardio e do pós-modernismo" (AMARAL, 2009, p.161). Nas próprias palavras de Frampton:

Os primórdios do Moderno, que remontam há pelo menos dois séculos, e o advento muito mais recente do pós-moderno, estão inextricavelmente ligados às ambiguidades introduzidas na arquitetura ocidental pela primazia dada ao cenográfico na evolução do mundo burguês. No entanto, a construção permanece essencialmente em caráter tectônico e não cenográfico e pode-se argumentar que ela é antes de tudo um ato de construção e não um discurso baseado na superfície, volume e plano, para citar 'Três lembretes para arquitetos' de Le Corbusier. (FRAMPTON, 1990, p.23) ${ }^{2}$

Frampton (1990), aqui, fala do convívio entre tectônica e cenografia e seu discurso evoca a face ontológica da arquitetura, sua essência enquanto construção. O autor não nega a importância da expressão formal arquitetônica, ele argumenta que esta expressão deve refletir seus aspectos construtivos: não deve ser somente uma expressão cenográfica, típica da arquitetura pós-moderna. Seus estudos são uma reação, como ele próprio diz, a uma aparente vitória na contemporaneidade do galpão decorado de Robert Venturi (FRAMPTON, 1990, p.20).

Em Studies in tectonic culture (1995), Frampton analisa a tectônica em obras de grandes arquitetos modernos, como Mies van der Rohe, Frank Lloyd Wright, Alvar Alto. criticando a arquitetura pós-moderna. Ele defende, assim, o retorno a uma arquitetura 
baseada na manipulação dos materiais, metafórica, mas que não seja reduzida a um simples símbolo linguístico ou dependente da comunicação da expressão visual de sua fachada. Frampton invoca uma arquitetura em relação com sua própria materialidade

Reforçando a oposição entre a tectônica e a cenografia apresentada em suas análises de 1983 e 1990, Frampton (1995) enfatiza a distinção didática proposta por Sekler entre edificações tectônicas e atectônicas. A expressão tectônica de um edifício seria uma conformidade da forma arquitetônica com sua estrutura e materialidade, enquanto uma estrutura atectônica seria utilizada quando a lógica estrutural de apoios e cargas é negligenciada e disfarçada na forma arquitetônica.

Uma análise dessas características no contexto modernista brasileiro é proposta por Bruno Santa Cecília (2008), que destaca em algumas obras "a utilização da estrutura como elemento gerador do espaço arquitetônico e definidor da expressão plástica" e a "simplificação intencional dos procedimentos e detalhes construtivos" (p.7). De fato, muitas edificações modernas brasileiras adotam estas estratégias, como a Catedral de Brasília de Oscar Niemeyer ou o Museu de Arte de São Paulo (MASP) de Lina Bo Bardi. Estes são, portanto, exemplos de obras arquitetônicas em que a expressão estética é intrinsecamente ligada às soluções estruturais: a estrutura destas edificações possui uma expressão plástica que pode ser classificada, inclusive, como didática, posto que revela explicitamente o funcionamento de seus sistemas de cargas e apoios.

A qualidade tectônica parece estar presente, portanto, em diversas linguagens: no organicismo de Frank Lloyd Wright e Aalto, no "estilo internacional" de Mies van der Rohe, no brutalismo do MASP, no modernismo de Niemeyer. Considerando a importância dessa qualidade para a compreensão da materialidade da arquitetura, ela deverá ser o ponto de partida para a análise que se propõe a seguir: a sua manifestação no Museu do Amanhã, de Calatrava, que é contraposta ao caráter atectônico do museu Guggenheim de Frank Gehry.

\section{O efeito Bilbao e o envelope fantasioso}

A análise do museu Guggenheim de Bilbao na Espanha é essencial para a compreensão da arquitetura de museus contemporâneos, uma vez que foi um marco da expressão formal arquitetônica e estabeleceu um movimento com implicações globais (JENKS, 2011), definindo uma estratégia de projeto que foi exportada para diversas localidades do mundo. Assim, a expressão arquitetônica, criada a partir de uma volumetria ornamental ou mesmo teatral, com design cenográfico, gerou uma imagem que se transformou em elemento fundamental para a abordagem publicitária.

É preciso destacar que a construção do Museu Guggenheim de Bilbao possui relação intrínseca com a tecnologia, posto que só foi viabilizada pelo seu emprego em nível avançado, desde o projeto até a organização do canteiro e construção. Para o desenvolvimento do projeto foi aplicada a modelagem digital paramétrica, (uma adaptação do programa (ATIA9), que trouxe também subsídios para a produção e montagem dos componentes altamente complexos do edifício. Os métodos construtivos inovadores permitiram uma redução do custo e prazo da obra (DI CRISTINA, 2005).

No entanto, a opção pela expressão simbólica significou a renúncia a toda e qualquer expressão tectônica. As fachadas do edifício se apresentam para todas as direções do terreno e não parecem estabelecer qualquer relação com o mesmo, sendo recobertas por uma pele de placas metálicas que formam curvas voluptuosas e brilhantes. 
Sobre o interior da edificação, elementos arquitetônicos tradicionais - como pilares, paredes e superfícies são revestidos, ocultados e distorcidos: "É difícil dizer o que é estrutural porque a estrutura foi dobrada e moldada além da norma" (NERO, 2004, p.20). ${ }^{4}$ Charles Jencks (2011) destaca o potencial metafórico da edificação, que suscita diversas leituras: "uma baleia, sereia ou uma criatura marinha gigante", com as linhas horizontais associadas a 'pernas sensuais', e o titânio brilhante, a "escamas de peixes" (JENCKS, 2011, posição 3164) .

Neste sentido, sob a constatação de que sua materialidade formal não apresenta as relações de carga e apoio de sua estrutura portante, e que "(...) aspectos construtivos se escondem sob as superfícies topológicas recobertas por folhas de titânio" (DI CRISTINA, 2005 p. 183), pode-se afirmar que o Guggenheim em Bilbao se coloca como arquitetura atectônica.

A edificação é, portanto, um exemplo típico da arquitetura contemporânea que Frampton crítica e classifica como cenográfica (1983, 1990). Ele inclusive cita explicitamente o museu, destacando a sua total indiferença quanto ao contexto topográfico e a desconformidade entre exterior e interior (JENKS, 2011, posição 3195).

Outros exemplos da estratégia global baseada no potencial midiático dos edifícios (LUPO, 2016) são o Museu Domus, de Arata Isozaki (cidade de La Coruña em 1995), o Museu de Arte Contemporânea de Oscar Niemeyer (cidade de Niterói em 1996), o Centro de Arte Contemporânea, de Bernard Tschumi (cidade de Tourcoing em 1997), e mais recentemente o Museu do Amanhã de Santiago Calatrava (cidade do Rio de Janeiro em 2015). Em todos os casos, trata-se de projetos de arquitetos de prestígio e reconhecimento internacional, que ambicionam uma forma arquitetônica destacada, com força publicitária ${ }^{6}$, capaz de atrair um fluxo turístico e investimentos internacionais (SANCHEZ, 2003). Este fenômeno foi classificado por Arantes (2010) como "a renda da forma" arquitetônica.

Este tipo de estratégia nem sempre está apoiada na tectônica da edificação. Por exemplo, o Museu Domus de Arata Isozaki pode ser considerado atectônico, posto que sua fachada frontal, revestida com pequenas placas de ardósia, mascara a volumetria da edificação que se desenvolve por trás. Por outro lado, o Museu de Arte Contemporânea de Niemeyer se eleva do solo por meio de um único grande pilar circular que sustenta toda a edificação, extraindo deste a força plástica de sua materialidade e expressando todo seu caráter tectônico. Apesar de adotarem abordagens tectônicas opostas, os dois museus ambicionam uma "renda da forma" e podem ser entendidos dentro da mesma lógica do museu Guggenheim em Bilbao: ambos evocam um design cenográfico (FOSTER, 2015, posição 1207) 7 e colocam ênfase no aspecto teatral da arquitetura (LUPO, 2016).

No sentido de subsidiar a investigação das relações entre as expressões tectônica e cenográfica, o Museu do Amanhã no Rio de Janeiro, será analisado a seguir, a partir das tensões existentes entre imagem e materialidade.

\section{O Museu do Amanhã e a tectônica}

O Museu do Amanhã se insere na lógica dos museus globais que procuram, por meio de uma forma arquitetônica cenográfica, projetar a cidade que os abriga no mercado mundial como potência cultural. Inicialmente, a ideia foi lançada pela Solomon R. Guggenheim Foundation, que tinha como objetivo a implantação do Projeto Guggenheim Brasil (ARANTES, 2010). Este projeto foi posteriormente abortado devido ao orçamento elevado e oposição do Instituto dos Arquitetos do Brasil, mas suas premissas foram recuperadas por meio da proposta da construção do projeto do 
arquiteto espanhol Santiago Calatrava (projeto executivo de arquitetura desenvolvido em parceria com o escritório local Ruy Rezende Arquitetura - RRA) (ROSENFIELD, 2015). Neste caso, não haveria o pagamento de royalties e a curadoria e conteúdo do museu estaria sob a responsabilidade da Fundação Roberto Marinho, do principal conglomerado de mídia brasileira (ARANTES, 2010).

A contratação de Santiago Calatrava afastou o Museu do Amanhã, em um primeiro momento, da arquitetura atectônica adotada por Frank Gehry para o museu Guggenheim em Bilbao, posto que Calatrava, inclusive por sua formação em engenharia civil, sempre demonstrou em suas obras uma preocupação evidente com a qualidade narrativa da estrutura. Nota-se em muitos dos seus edifícios a manifestação visual de estruturas semelhantes a esqueletos zoomórficos que se articulam na constituição da forma (JENKS, 2011, posição 3446). Ele é inclusive citado pelo próprio Frampton (1995) como um dos engenheiros de destaque pela preocupação com aspectos da estrutura que "transcende[m] a lógica do cálculo" (p. 335), e trouxeram contribuição seminal para a cultura dos edifícios modernos: um notável "definidor de formas" por mérito próprio (p. 335).

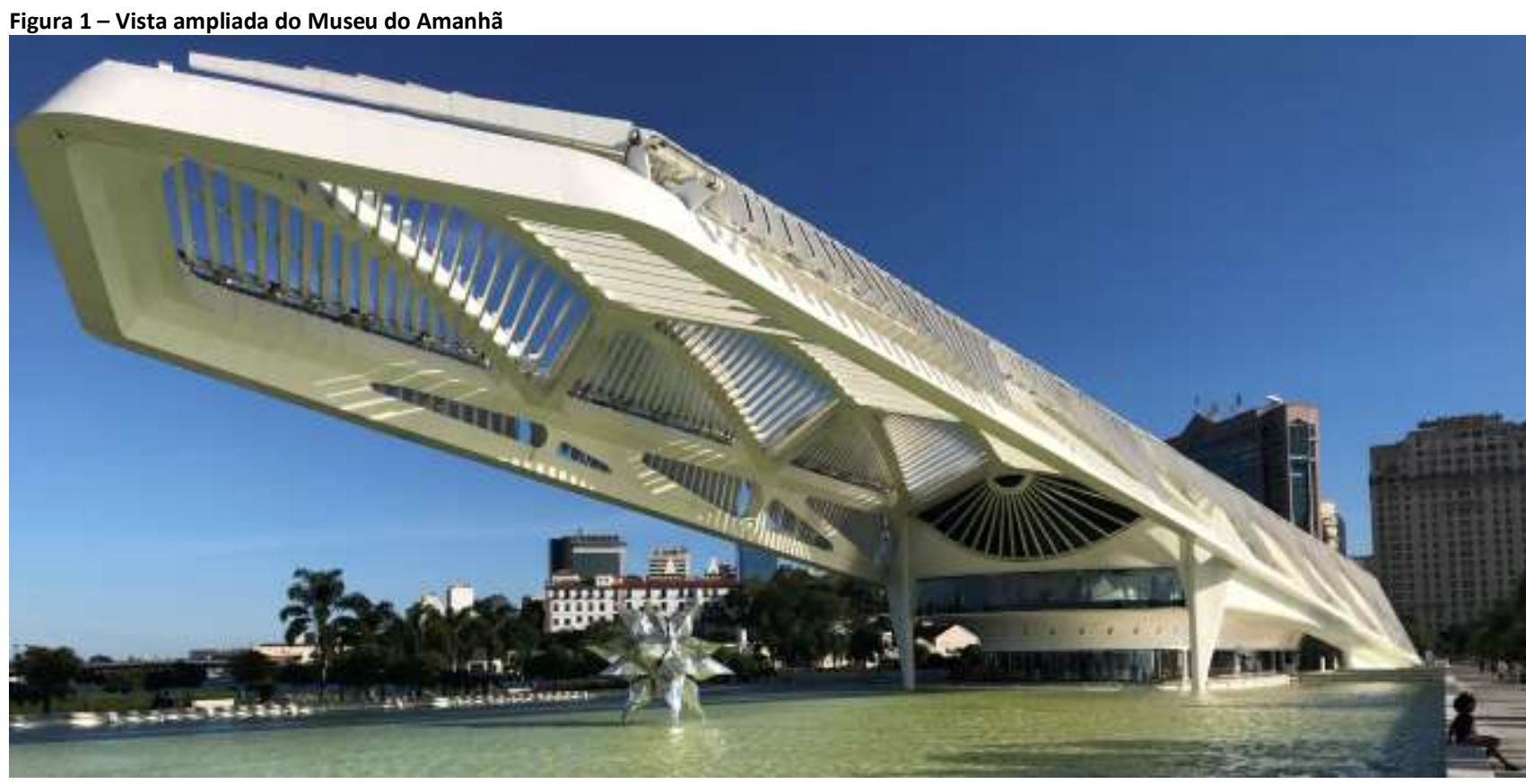

Fonte: o autor.

O Museu do Amanhã foi instalado no Píer Mauá, às margens da Bahia de Guanabara, a partir de um projeto em que a estrutura é explicitada de forma clara e se investe de valores simbólicos e expressividade material. Neste sentido, o edifício contempla a dimensão "material, construtiva e tátil" da arquitetura revelando qualidade tectônica latente. Entretanto, a falta de enraizamento do edifício na cultura e no entorno, que os teóricos do século XIX tanto enfatizaram em suas colocações sobre tectônica, suscita críticas, conforme veremos adiante.

No que diz respeito à materialidade da edificação propriamente dita, sua estrutura longilínea e horizontal (Figura 1) apresenta uma área central sólida que sustenta e é encimada por uma enorme cobertura metálica esquelética, projetada em dois enormes balanços (Figura 2). Nesta cobertura, com comprimento superior a $330 \mathrm{~m}$, e balanços de $65 \mathrm{~m}$ (entrada) e $70 \mathrm{~m}$ (fachada mar) foram instaladas placas solares móveis que se ajustam conforme a época do ano de acordo com a posição do sol. Os apoios no solo, 
BRAGA, Diogo Ubaldo et al..

Museu do Amanhã e articulações da expressão tectônica e condição cenográfica

que sustentam toda esta estrutura monumental, são poucos e bem demarcados (Figura 3). O interior permite a visualização íntegra do edifício, concebido como um pavilhão.

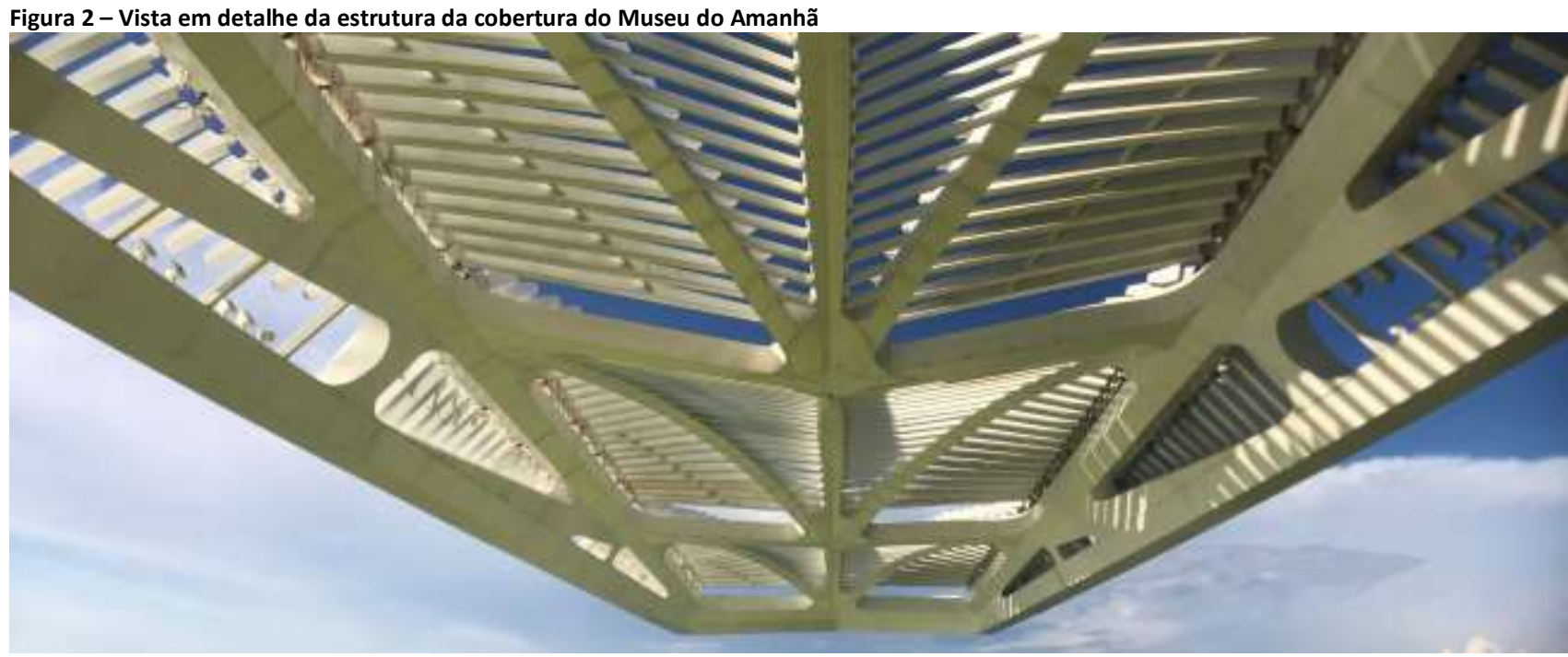

Fonte: o autor.

Figura 3 - Cobertura do Museu do Amanhã com painéis solares

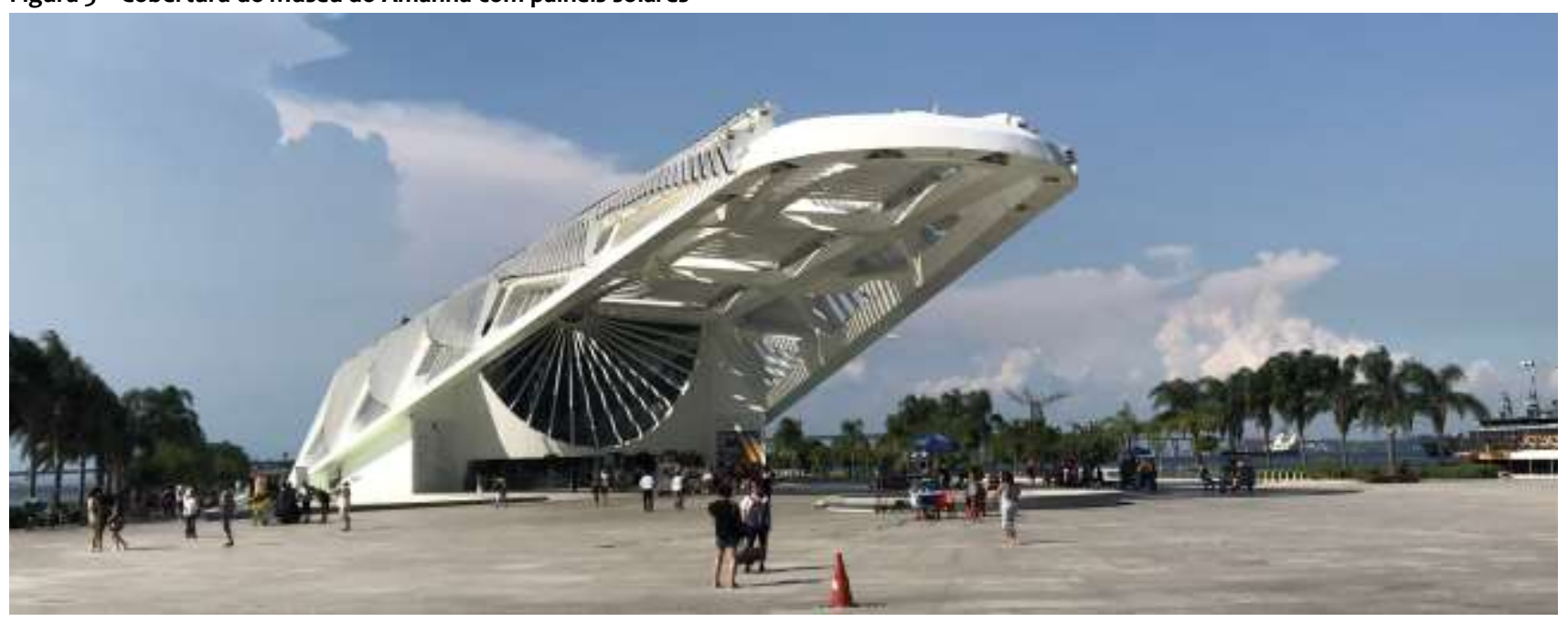

Fonte: 0 autor.

Os estudos iniciais previam o acesso por meio de duas rampas laterais, que davam acesso a uma grande vidraça com a vista sobre a baia da Guanabara, com destaque para a Ilha Fiscal e Niterói. A saída seria em direção à praça Mauá. Entretanto, "[...] a criação da narrativa museal considerou a importância de se concluir o percurso com a mirada para a baía, de modo a suscitar no visitante a reflexão sobre o amanhã" (LUPO, 2019, p. 229). Desta forma, o foco nos efeitos cenográficos do edifício inverteu a lógica de funcionamento, e o acesso foi direcionado para as escadas laterais, que conduzem a um mezanino do qual partem duas galerias laterais. $O$ espaço de exibição apresenta um telhado de $10 \mathrm{~m}$ de altura (ROSENFIELD, 2015). No centro, estão o auditório e módulos permeáveis com conteúdo interativo e virtual. A vidraça com vista está na parte posterior, alcançada depois de atravessado o espaço de exposição, e as duas rampas laterais servem para a volta do percurso. À saída do museu, uma ampla varanda lateral dá acesso ao espelho d'água e ao "parque" (RHEINGANTZ et al. 2017). Muito embora a cobertura cubra a área central sólida, sua estrutura é permeável e possibilita a visão do volume coberto, reiterando a expressão tectônica. 
Rheingantz et al (2017) empreenderam um estudo propondo um olhar sociotécnico para situar o empreendimento e procuram entender como as espacialidades se produzem, a partir de uma rede que inclui "[...] objetos, materialidades, tecnologia natureza, organismos e seres humanos" (p. 388). Dentro da perspectiva deste estudo, a implantação aparece como controversa: as dimensões do parque no entorno do perímetro do cais são consideradas insuficientes para proporcionar aos visitantes uma vista da baia da Guanabara. O lago existente, que procura criar a sensação de que o edifício paira sobre o mar, gera uma sensação de redundância (RHEINGANTZ et al. 2017).

Apesar das controvérsias sobre o funcionamento ou a inserção no entorno, é possível classificar a expressão formal do Museu do Amanhã como essencialmente tectônica, posto que a lógica estrutural da edificação é de fácil identificação visual: a cobertura metálica se estrutura em treliças e se apoia no chão em dois pontos fixos (um de cada lado, no local indicado por um círculo na figura 4). O material utilizado como solução para os grandes vãos da cobertura, com poucos apoios, é o aço, e sua estrutura conta com três tipos principais de peças: "os banzos, estruturas principais que traçam as linhas retas da obra; os painéis de chapas reforçadas; e as aletas, estruturas de seção variada, feitas a partir de perfis de chapa" (INSTITUTO, 2015, n.p.) Por sua vez, a edificação interna utiliza o concreto e se apoia nos pontos indicados por meio de setas na Figura 4. A materialidade do edifício tem grande expressão plástica.

Conforme afirma Frampton (1995), “o potencial técnico completo de qualquer edifício deriva de sua capacidade em articular tanto os aspectos poéticos quanto os cognitivos de sua substância" (p. 26). O museu do Amanhã foi concebido a partir de uma ideia de leveza, que faz com que o edifício apareça "quase que flutuando acima do mar, como um barco, um pássaro ou uma planta. Para Rosenfield (2015) a "estrutura arquetípica introduzida dentro do edifício" confere uma simplicidade ao Museu do Amanhã, que permite uma versatilidade de funcionamento ao mesmo tempo em que explicita clareza na leitura da solução estrutural."

Figura 4 - Croqui da elevação lateral nordeste do Museu do Amanhã com o apontamento de sua lógica estrutural

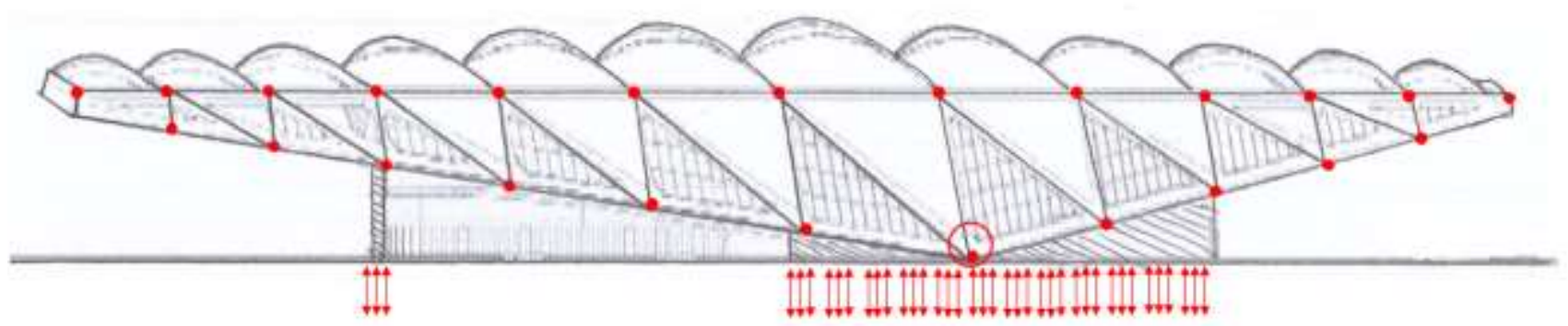

Fonte: croqui realizado pelo autor

Existe, portanto, uma significativa diferença entre o Museu Guggenheim em Bilbao e o Museu do Amanhã no Rio de Janeiro. Enquanto, no primeiro caso, o edifício possui volutas metálicas exercendo a função de "pele" ornamental com configuração própria, ocultando a estrutura e deixando vazios internos, no Museu do Amanhã a cobertura é uma solução estrutural que permite a visualização dos pilares e apoios. Calatrava, ao contrário de Gehry, se destaca por suas edificações com forte expressão estrutural (FIGUEIREDO, 2010), mas também pelo valor simbólico que confere às mesmas. O Museu do Amanhã se insere no contexto de obras que poderiam ser chamadas de centrípetas, com pretensão de articular todo seu entorno e de se afirmar como obra original e única, com poder de "renda da forma", como diria Arantes (2010). 
Porém, apesar de sua natureza tectônica evidente, fato é que a crítica de Venturi, Brown e Izenour (2003) ao monumento tardo-moderno pode também se aplicar ao museu: o volume e sua articulação formal se apresentam como o próprio ornamento declaradamente imitando uma bromélia - como o enorme edifício figurativo em formado de pato de Long Island. Dentro desta perspectiva, o Museu do Amanhã, e também o Guggenheim em Bilbao, seriam enquadrados na categoria de edifício "pato". Este seria, então, um ponto de interseção conceitual entre as edificações, em outros aspectos, tão distantes.

Outra questão que se destaca no Museu do Amanhã é a negligência com relação ao acervo, que é inexistente: as exposições se desenvolvem por meio da reprodução de vídeos e uma eventual materialidade se manifesta, por meio de maquetes e alegorias, como na lógica das atrações dos parques de diversão. Todavia, este fato é secundário. Em entrevista a Lupo (2019), o responsável pelo detalhamento da museografia - Vasco Caldeira - afirma: "o edifício foi projetado para ser um espaço vazio. A recomendação era: façam o que quiserem, mas não estraguem a arquitetura com a museografia" ( $p$. 227). Reafirma-se, portanto, que a atração principal do museu é a sua própria forma, colocada como cenografia.

A preocupação com a manutenção das características da arquitetura não se coloca, entretanto, como um impedimento à plena utilização do espaço - mas revela, justamente, um desejo de que a flexibilidade de seu uso seja preservada. Neste sentido, e com vistas a criar uma narrativa de evolução em busca do Amanhã, a museografia parece ter sido capaz de se apoderar do principal atributo de delimitação dos espaços interiores, que é a continuidade e fluidez. Embora a sua delimitação ocorra, seja por meio de curvas ou planos, eles não se fecham completamente, mas deixam entrever o todo. A Figura 5 - corte transversal - mostra o grande vão central no pavimento térreo e a fluidez do espaço e sua relação com a cobertura, no segundo pavimento. O espaço interior apropriado pela museografia cria, portanto, uma liberdade de percurso, por meio da qual "[...] o suposto livre acesso, aparentemente sem pistas a serem seguidas, proporciona nos sujeitos discursivos a ilusão de livre escolha do caminho a percorrer, imputando-lhes também a responsabilidade de sua tomada de posição" (DARÓz; SOUSA, 2019, p. 147).

Figura 5 -Seção transversal do Museu do Amanhã

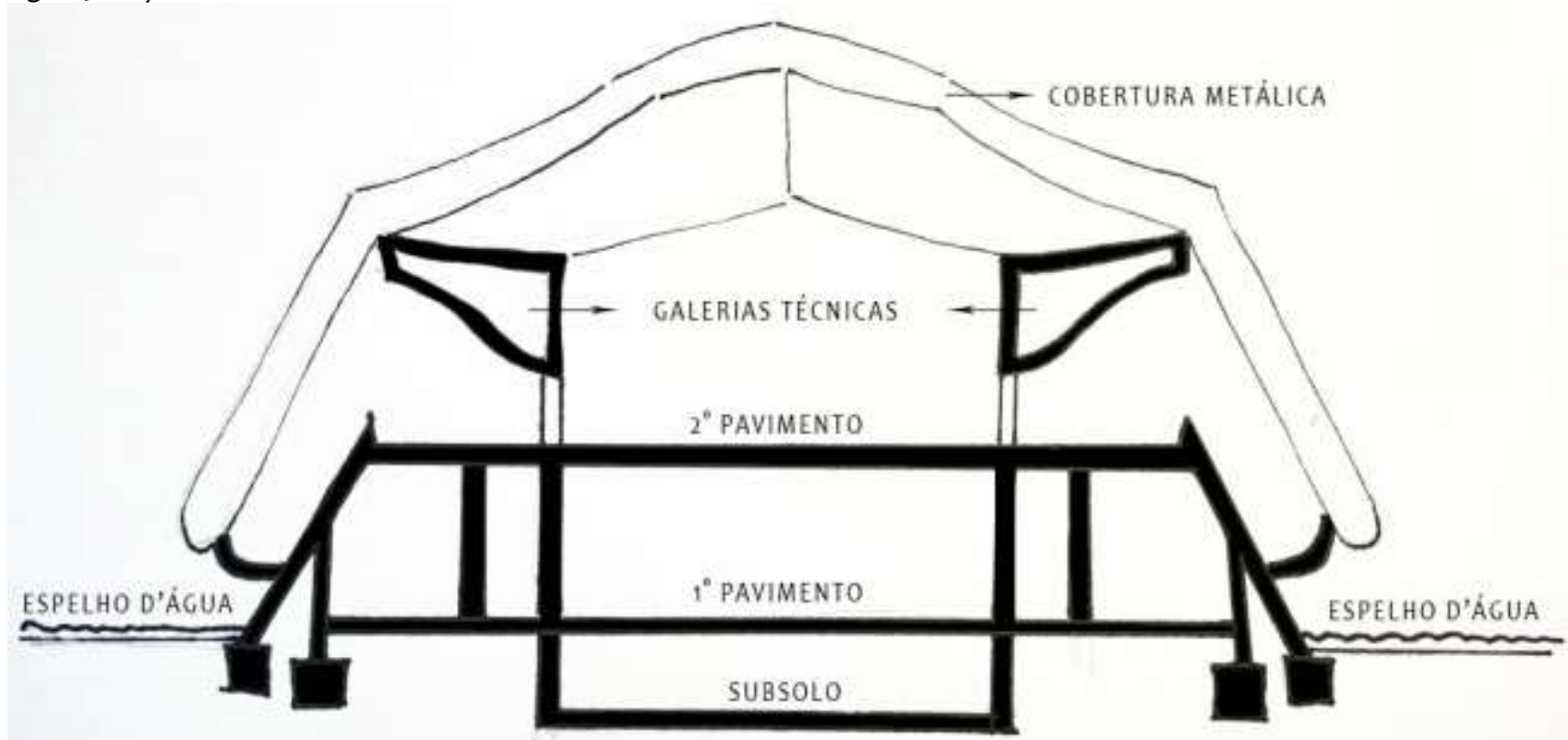

Fonte: croqui realizado pelo autor. 
A cenografia do Museu do Amanhã não se manifesta, assim, no aspecto de sua materialidade, mas na sua expressão, na sua flexibilidade interior e no uso ao qual se propõe, como cenário de uma cidade turística. Ao mesmo tempo, ela se coloca enquanto imagem que procura remeter as soluções formais a uma estética compatível com o Amanhã (LUPO, 2019). O potencial tectônico da estrutura gera o espaço arquitetônico e define sua forma. No entanto, este potencial é explorado para configurar uma cenografia monumental espetacular e inserir a cidade no mercado global.

\section{Considerações finais}

A partir da análise empreendida, pode-se perceber que a arquitetura dos museus contemporâneos tem adotado soluções tecnológicas que nem sempre são justificadas do ponto de vista construtivo, mas são utilizadas com o objetivo de produzir imagens fortes e emblemáticas.

Este fenômeno foi absorvido no Brasil, em especial no Rio de Janeiro, em um contexto político e econômico muito particular, em meio à articulação da Copa do Mundo de futebol e dos Jogos Olímpicos. O Museu do Amanhã se materializou, portanto, a partir de uma arquitetura ambígua: se por um lado ela se mantêm representativa sob o ponto de vista da tectônica, por outro, ela contribui para criação de uma cenografia para a cidade - seu principal objetivo. Assim, conceitos que, para a literatura, se apresentam, por vezes, contraditórios, parecem se somar no Brasil nesse contexto singular.

Essa condição não é inédita, entretanto. A arquitetura de Frank Lloyd Wright, por exemplo, é uma referência para Frampton (1995), em termos de manipulação dos materiais, ao mesmo tempo que o seu museu Guggenhein é considerado "um ícone neo expressionista" por excelência. O MASP, de Lina Bo Bardi é citado por Santa Cecilia (2005) como expressão tectônica, e considerado na literatura como exemplo brutalista indiscutível. Assim, as possibilidades de articulação entre a materialidade e a condição cenográfica são múltiplas.

A utilização da técnica e da tecnologia no Museu do Amanhã se integra ao contexto de importação do "efeito-Bilbao" e procura também a criação de uma imagem forte e emblemática, com valor de marca. Neste sentido, a crítica de Venturi, Brown e Izenour (2003) à arquitetura tardo-moderna também é pertinente ao Museu do Amanhã, podendo-se entendê-lo como edificação com aspectos cenográficos - um "pato" - por sua articulação formal espetacular - mas também "galpão decorado", posto que possui também elementos isolados que podem ser entendidos como ornamentais.

Estes elementos isolados são colocados na edificação e em seu entorno imediato para a atribuição de certas características ou fomentar determinada narrativa, que pode ser de sustentabilidade ou de aparência tecnológica. É o caso das placas fotovoltaicas que possuem formato não convencional e se movem por um sistema motor próprio para se adequar à melhor posição solar, ou o caso das demais placas fotovoltaicas em forma de palmeira instaladas no pátio do museu para que os transeuntes possam carregar seus celulares e outros equipamentos (Figura 6), este, um evidente ornamento figurativo. 
BRAGA, Diogo Ubaldo et al..

Museu do Amanhã e articulações da expressão tectônica e condição cenográfica

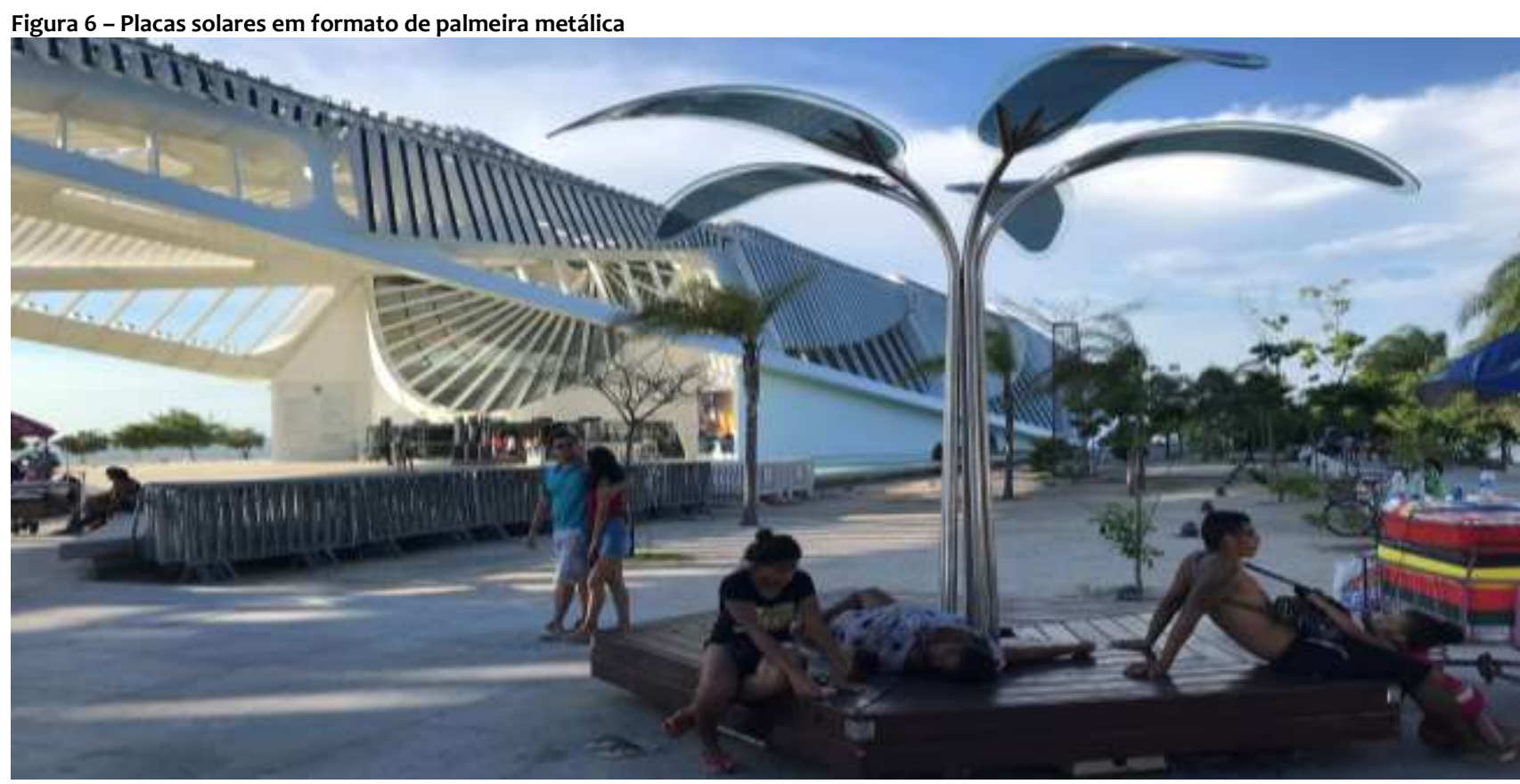

Fonte: $o$ autor.

Estes aparatos moventes que sustentam o discurso tecnológico parecem ter se inspirado nos cenários de filmes de ficção científica, ou mesmo na movable city do grupo Archigram. Desta forma, ao contrário do que declara Calatrava (2015), o Museu do Amanhã se apresenta como um objeto totalmente discrepante do entorno imediato, do passado ou do presente. Neste sentido, mesmo arquitetos que não são considerados, a princípio, como high-tech, podem se apropriar desta estética.

Frampton (1995) utiliza o discurso da tectônica contrapondo e criticando a tendência da arquitetura pós-moderna e contemporânea de criação de edifícios cenográficos e fantasiosos. No caso do Museu do Amanhã, é inegável que ele foi concebido para compor a cenografia de uma cidade que ambiciona se posicionar no mercado global enquanto potência cultural, muito embora em sua materialidade e concepção estrutural ele se apresente como uma edificação tectônica. Esta condição se afirma a partir das motivações de sua construção, das influências que sofreu de outras obras, do contexto em que ele foi edificado, mas, também, do uso a que se propõe e de sua utilização. Assim, se considerarmos a monumentalidade e teatralidade (cenográfica) da forma, a intenção simbólica, a materialização de um valor de marketing global, é possível concluir que mesmo a arquitetura tectônica pode ser cenográfica.

Portanto, o debate acerca do caráter tectônico da arquitetura não deve se opor ao reconhecimento do caráter cenográfico, como se fossem mutuamente excludentes. A materialidade tectônica, a manifestação plena de uma lógica estrutural e construtiva pode, efetivamente, se colocar como suporte para uma arquitetura cenográfica. Afinal, a arquitetura se tornou espetáculo, no contexto de uma cultura permeada pela produção de narrativas, geradas a partir de imagens e referências a diferentes códigos. As classificações e filiação a estilos e linguagens não conseguem abarcar a complexidade formal e espacial, as interseções e ambiguidade das construções em suas articulações com o espaço.

\section{Agradecimentos}

O presente trabalho foi realizado com apoio da Coordenação de Aperfeiçoamento de Pessoal de Nível Superior Brasil (CAPES) e do Conselho Nacional de Desenvolvimento Científico e Tecnológico (CNPq). 


\section{Notas}

(1) Venturi chama (de maneira jocosa) esse expressionismo abstrato do modernismo de "arquitetura pato", em homenagem ao "Patinho de Long Island", um edifício em formato de pato que funcionava de chamariz para as atividades comerciais de uma propriedade avícola. Esta estrutura, não possuindo nenhum sentido formal abstrato, serviu como instrumento metafórico essencial para a crítica de Venturi ao modernismo e sua abolição radical ao ornamento.

(2) Tradução própria do trecho: "The beginnings of the Modern, dating back at least two centuries, and the much more recent advent of the Post-modern, are inextricably bound up with the ambiguities introduced into Western architecture by the primacy given to the scenographic in the evolution of the bourgeois world. However, building remains essentially tectonic rather than scenographic in character and it may be argued that it is first and foremost an act of construction rather than a discourse predicated on the surface, volume and plan, to cite Le Corbusier's 'Three Reminders to Architects'”.

(3) Edificação concebida através de uma massa de forma sólida onde são realizadas supressões volumétricas.

(4) Tradução própria do trecho: "It is difficult to tell what is structural because structure has been bent and molded beyond the norm. Design and tectonics are merged into one"

(5) Tradução própria do trecho: "Indeed, most readers found in the shapes connotations of nature. The flowing horizontals were like 'sensuous legs', the glistening titanium shingles were like 'fish scales' (and several people read the building as a whale, mermaid or giant water creature)".

(6) Utiliza-se aqui como publicidade o conceito explicitado em Barbosa (2015) que diz que ela "(...) exprime suas três dimensões: seu valor utilitário, seu valor imaginário psicológico e seu valor como símbolo social. A publicidade ainda tende para o psicológico e o cultural para atingir o consumidor" (BARBOSA, 2015, posição 362).

(7) Citação da localização em texto em sua posição correspondente e não em página, posto que a edição do livro consultado está em formato digital de e-book Kindle.

\section{Referências}

AMARAL, I. Quase tudo que você queria saber sobre tectônica, mas tinha vergonha de perguntar. Pós. Revista do Programa de Pós-Graduação em Arquitetura e Urbanismo da FAUUSP, São Paulo, n. 26, p. 148-167, dez. 2009. DOI: https://doi.org/10.11606/issn.2317-2762.voi26p148-167.

ARANTES, Pedro Fiori. Arquitetura na era digital-financeira: desenho, canteiro e renda da forma. 2010. Tese (Doutorado em Tecnologia da Arquitetura) - Faculdade de Arquitetura e Urbanismo, Universidade de São Paulo, São Paulo. Disponível em: https://repositorio.unb.br/handle/10482/32254. Acesso em: 06 out. 2018.

BARBOSA, Ycarim. O turismo e os não lugares. Goiânia: London 7, 2015. E-book.

CALATRAVA, Santiago. Portfólio, 2015. Disponível em: https://calatrava.com/projects/obelisk-haifa.htmll. Acesso em: 08 de out. 2018.

CANTALICE II, Aristóteles de Siqueira Campos. Redescobrindo a arte cientifica tectonica. Oculum Ensaios, Campinas, v. 15, n. 2, p. 247-269, 2018. DOI: https://doi.org/10.24220/2318-0919v15n2a3849.

CHOAY, Françoise. A Alegoria do Patrimônio. Tradução Luciano Vieira Machado. São Paulo: Estação Liberdade/ Unesp, 2006.

DARÓZ, Elaine; SOUSA, Lucilia M. A. e. No museu, o Amanhã no entrelaçamento entre história e memória. Revista Letras Raras, Campina Grande, v. 8, n. 2, p. Port. 133-149 / Eng. 134-149, jun. 2019. ISSN 2317-2347. DOI: http://dx.doi.org/10.35572/rlr.v8i2.1377.

DI CRISTINA, Giuseppa. Poetry in Curves: The Guggenheim Museum in Bilbao. The Visual Mind II, 2005. Disponível em: https://epdf.pub/the-visual-mind-ii-leonardo-books.html. Acesso em: 13 abr. 2020. 
BRAGA, Diogo Ubaldo et al..

Museu do Amanhã e articulações da expressão tectônica e condição cenográfica

FIGUEIREDO, Gonçalo J. Uma visão escultórica da obra de Santiago Calatrava. 2010. 132 f. Dissertação (Mestrado em Artes Visuais) - Departamento de Artes Visuais e Design, Universidade de Évora, Évora, 2010. Disponível em: http://hdl.handle.net/10174/10902. Acesso em: 13 abr. 2020.

FOSTER, Hal. Complexo arte - arquitetura. Tradução Célia Euvaldo. São Paulo: Cosac Naify, 2015. E-book.

FRAMPTON, Kenneth. Rappel a l'Ordre: The Case for the Tectonic. Architectural Design, [S.I.], v. 60, n. 3-4, 1990. p. 19-25. Disponível em: https://suw.biblos.pk.edu.pl/downloadResource\&mld=213385. Acesso em: 13 abr. 2020.

FRAMPTON, Kenneth. Studies in Tectonic Culture. Cambridge: MIT Press, 1995.

FRAMPTON, Kenneth. Toward a Critical Regionalism: Six points for an Architecture of Resistance. In: FOSTER, Hal (ed.) The Anti-Aesthetic: Essays on postmodern culture. Washington: Bay Press, 1983.

GELINSKI, G. Obra-Monumento de Calatrava no Píer Mauá. Finestra, [S.I.], v. 88, 2014. Disponível em: https://arcoweb.com.br/finestra/arquitetura/santiago-calatrava-museu-amanha-riojaneiro-2014. Acesso em: $21 \mathrm{fev}$. 2016.

HARTOONIAN, Gevork. Architecture and Spectacle: A Critique. Londres: Routledge, 2012. ISBN: 9781409422938.

JENCKS, Charles. The Story of Post-Modernism: Five Decades of the Ironic, Iconic and Critical in Architecture. Londres: John Wiley \& Sons, 2011. E-book. ISBN-13: 978-0470688953. ISBN-10: 0470688955.

KIEFER, Flavio. Arquitetura de Museus. Revista ARQTEXTO, Porto Alegre, v. 1, n.2, p. 12-25, 2001. ISSN: 1518-238X. Disponível em: https://www.ufrgs.br/propar/publicacoes/ARQtextos/PDFs_revista_1/1_Kiefer.pdf. Acesso em:22 abr. 2018.

LUPO, B. M. O museu como espaço de interação: arquitetura, museografia e museologia. Revista CPC, São Paulo, v. 14, n. 27, p. 217-243, 29 jul. 2019. Disponível em: http://www.revistas.usp.br/cpc/article/view/156220. Acesso em: Acesso em: 13 abril 2020.

LUPO, Bianca. Museus como fenômeno de massas: arte, arquitetura e cidade. In: SEMINÁRIO DE HISTÓRIA DA CIDADE E DO URBANISMO: VISÕES E REVISÕES DO SÉCULO XX. 14., 2016, São Carlos. Anais [...]. São Carlos: USP, 2016. p. 533-539. Disponível em: https://www.iau.usp.br/shcu2016/anais/wp-content/uploads/pdfs/62.pdf. Acesso em: 13 abril 2020.

MONTANER, Josep Maria. Museos para el nuevo siglo. Barcelona: Gustavo Gili, 1995.

NERO, Irene. Computers, Cladding, and Curves: The Techno-Morphism of Frank Gehry's Guggenheim Museum in Bilbao Spain. 2004. Tese (Doutorado em Filosofia) - Escola de Artes Visuais e Dança, Universidade do Estado da Flórida, Tallahasse, 2004.

RAMÍREZ-MONTAGUT, Mónica. ¿ Por qué Frampton retoma la teoría de Semper? DC Papers. Revista de crítica y teoría de la arquitectura, Barcelona, n. 1, p. 105-111, 1998. ISSN-e: 1887-2360.

RHEINGANTZ, Paulo Afonso et al. Arena do Morro e Museu do Amanhã: dois lugares em ação. URBE. Rev. Bras. De Gestão Urbana, Curitiba, v. 9, n. 3, p. 387-400, dez. 2017. DOI: http://dx.doi.org/10.1590/2175-3369.009.003.a002.

ROSENFIELD, Karissa. Santiago's Calatrava Museum of Tomorrow opens in Rio de Janeiro. 17 dez. 2015. Archdaily [online]. ISSN: 0719-8884. Disponível em: https://www.archdaily.com/778998/santiago-calatravas--museum-oftomorrow-opens-in-rio-de-janeiro\#_=.. Acesso em: 09 out. 2019.

SANCHEZ, Fernanda. A reinvenção das cidades para um mercado mundial. 2. ed. Chapecó: Argos, 2003.

SANTA CECÍLIA, Bruno Luiz Coutinho. Tectônica moderna e construção nacional. MDC - Revista de Arquitetura e Urbanismo, Belo Horizonte/Brasília, n.1, p.6-9, 2005. 
BRAGA, Diogo Ubaldo et al..

Museu do Amanhã e articulações da expressão tectônica e condição cenográfica

SASSEN, Saskia. The Global City: New York, London, Tokyo. Princeton: Princeton University Press, 2001. E-book. ISBN: 9781400847488.

SEKLER, Eduard. Structure, Construction, Tectonics. In: GYORGY, Kepes (Org.) Structure in Art and in Science. Londres: Studio Vista, p. 89-95, 1965.

SHEPPARD, Adrian. The Return of Expressionism and the architecture of Luigi Moretti. Montreal: McGill University Online, 2016. Disponível em: https://www.mcgill.ca/architecture/files/architecture/ExpressionismMoretti.pdf. Acesso em: 13 abr. 2020.

VENTURI, Robert; BROWN Denise Scott; IZENOUR, Steven. Aprendendo com Las Vegas: o simbolismo (esquecido) da forma arquitetônica. São Paulo: Cosac \& Naify, 2003.

\section{${ }^{1}$ Diogo Ubaldo Braga}

Arquiteto e Bacharel em Direito. Mestrando. Arquiteto Analista no Conselho de Arquitetura e Urbanismo de Minas Gerais. Endereço postal: Rua Paraíba, 697 - Savassi Belo Horizonte, Minas Gerais, Brasil, 30130-141.

\section{Maria Luiza Almeida Cunha de Castro}

Arquiteta. Doutora. Professora permanente do Programa de Pós graduação em Ambiente Construído e Patrimônio Sustentável UFMG. Endereço postal: Rua Paraíba, 697 - Savassi Belo Horizonte, Minas Gerais, Brasil, 30130-141.

\section{Marco Antônio Penido de Rezende}

Arquiteto. Doutor. Professor permanente do Programa de Pós graduação em Ambiente Construído e Patrimônio Sustentável UFMG. Endereço postal: Rua Paraíba, 697 - Savassi Belo Horizonte, Minas Gerais, Brasil, 30130-141.

4 João Luiz van Ham Mello

Turismólogo. Mestrando. Endereço postal: Endereço postal: Rua Paraíba, 697 - Savassi Belo Horizonte, Minas Gerais, Brasil, 30130-141. 